This paper is published in the open archive of Mid Sweden University

DIVA http://miun.diva-portal.org

with permission of the publisher

Citation for the peer-reviewed published paper:

Walter K, Paulsson M, Wackerberg E. Energy efficient refining of Black spruce TMP by using acid hydrogen peroxide : Part 1. A pilot plant study. Stockholm: SPCI; Nordic Pulp \& Paper Research Journal. 2009;24(3):255-265.

URL to article at publishers site:

http://dx.doi.org/10.3183/NPPRJ-2009-24-03-p255-265 


\title{
Energy efficient refining of black spruce TMP by using acid hydrogen peroxide: Part 1. A pilot plant study
}

\author{
Karin Walter and Magnus Paulsson, Eka Chemicals AB, Bohus, Sweden, and Mid Sweden University, Sundsvall, Sweden, Eva Wackerberg, \\ Eka Chemicals AB, Bohus, Sweden
}

KEYWORDS: TMP, Black spruce, Energy reduction, Hydrogen peroxide, Ferrous sulphate, Refining, Inter-stage treatment, Pulp and paper properties, Fenton's reagent

SUMMARY: The potential of using acid hydrogen peroxide for lowering the electrical energy consumption during production of Black spruce (Picea mariana) thermomechanical pulp (TMP) was investigated. The chemical system, which consisted of ferrous sulphate, hydrogen peroxide and optionally an enhancer [ethylenediaminetetraacetic acid (sodium salt), 3,4-dimethoxybenzyl (veratryl) alcohol or oxalic acid/sodium oxalate], was evaluated as an inter-stage treatment where the primary refiner was used as a mixer. The approach has the advantage of minimising the capital investment needed for implementation, thus being directly applicable in a thermomechanical pulping process consisting of two or more refiners in series.

The results obtained in a pilot plant trial revealed that is was possible to significantly reduce the specific energy consumption by approximately 20 and $35 \%$ to a freeness value of $100 \mathrm{ml}$ CSF by using 1 and $2 \%$ hydrogen peroxide, respectively. The energy reduction could be obtained without any substantial change in fibre length, fractional composition of the pulp or tensile strength of the paper. The tear strength was slightly reduced however, as was the pulp yield. The major drawback with the acid hydrogen peroxide system was a reduction in brightness by at least 6 brightness units. The addition level of ferrous sulphate was too high and the possibility to reducing the discoloration should be considerable when the chemical system is optimized.

\section{ADDRESSES OF THE AUTHORS: Karin Walter \\ (karin.walter@akzonobel.com), Magnus Paulsson (magnus.paulsson@akzonobel.com): Eka Chemicals AB, SE-445 80 Bohus, Sweden, and Mid Sweden University, FSCN, SE-851 70 Sundsvall, Sweden. \\ Eva Wackerberg (eva.wackerberg@akzonobel.com): Eka Chemicals AB, SE-445 80 Bohus, Sweden. Corresponding author: Karin Walter}

Enhanced production and efficient utilization of lignocellulosic products are issues of great importance to both industry and society. The production of mechanical and chemimechanical pulps is an efficient way of using the available virgin fibre resources since the yield of these manufacturing processes is high and the environmental impact relatively low. The light scattering (opacity) and bulk (stiffness) properties of high-yield pulps are exceptional and not easily obtainable with other pulp types. The poor brightness stability, and for some wood raw materials and pulping processes, the low maximum obtainable brightness (whiteness) level, are the major obstacles for using high-yield pulps also in long-life, high-quality papers. Furthermore, mechanical and chemimechanical pulping processes are energy intensive and represent about $20 \%$ of the electrical energy demand of papermaking in the world (Münster et al. 2005). The development of innovative solutions that substantially reduce the energy consumption while maintaining pulp quality is therefore an important issue for the pulp and paper industry globally.

The amount of electricity needed for fibre separation and development is dependent on many factors such as the type of wood raw material used, the pulping process chosen and the intended end-use of the produced pulp. The specific energy consumption (SEC) for producing thermomechanical pulps (TMPs) can be up to 3-3.5 MWh/t (Jackson, Wild 1999; Ali (Viforr), Salmén 2005; Francis et al. 2006; Viljakainen 2006), and consequently the electrical power cost has a great impact on the total production cost and thus the profitability. The significant increase in energy costs that has taken place during recent years, due to a more deregulated power supply in combination with legislations or incentives to reduce the greenhouse gas emissions has intensified the work towards energy efficiency in the refining process. The TMP systems installed today are expected to have at least $10 \%$ lower energy consumption than the systems installed previously (Sabourin 2007), but this is not enough and many companies are pursuing new and more energy efficient solutions that are also applicable in existing installations.

A vast number of energy reducing strategies and technologies ranging from process control and machinery to biotechnology have been proposed (cf. e.g., Cannell 1999; Rodden 2003). Several concepts with increased processing temperature and intensity in connection to the refining process, e.g., ThermoPulp, high-temperature chemithermomechanical pulping (HT-CTMP) and RTSTMP, have been developed during the last decades (Münster, Dahlqvist 1995; Sabourin et al. 1996; Höglund et al. 1997; Vesterlind, Höglund 2006). It has also been shown that mechanical compressive treatments of wood chips prior to refining (Frazier, Williams 1982; Sabourin 1998; Kure et al. 1999) lowers the specific energy consumption, as does the introduction of a low-consistency final refining stage (Musselman et al. 1996). Chemical (e.g., selective sulfonation, oxalation, ozonation, alkaline treatments) and enzymatic (e.g., cellulase, hemicellulases, laccase or pectinase) pre-treatments of wood chips prior to refining, or inter-stage treatments of coarse pulps have also been suggested (Hartler 1980; Janson, Mannström 1981; Axelson, Simonson 1983; Petit-Conil, de Choudens 1998; Pere et al. 2000; Mansfield 2002; Peng et al. 2003; Swaney et al. 2003; Meyer et al. 2005). For example, addition of alkaline 
hydrogen peroxide to refiners is a well known technology that besides brightening of the pulp also can lower the energy demand (Åkerlund et al. 1979; Strunk, Meng 1989; Harrison et al. 2008). The energy reduction obtainable in mill scale is, however, limited and the problem with scaling is common when using this technology. The use of magnesium based alkali sources can, however, reduce the calcium oxalate scaling issues (Harrison et al. 2008). Some of the above mentioned processes can reduce the specific energy consumption considerably, but seldom without detrimentally changing the pulp and paper properties. Furthermore, many of the technologies are capital intensive and/or have a high operational cost that results in no or very small financial benefits for the mills.

Fungal treatment of wood chips or coarse pulp has been explored since the 1970s to lower the specific energy consumption during mechanical pulping (Ander, Eriksson 1975; Bar-Lev et al. 1982; Akamatsu et al. 1984; Leatham et al. 1990; Setliff et al. 1990; Akhtar et al. 1993, Akhtar et al. 1998; Agarwal, Akhtar 2000). White-rot fungi are of prime interest since the potential to degrade both wood polysaccharides and lignin exists. There is, however, a substantial variability both among and within fungal species with regard to lignin selectivity. The benefits by using white-rot fungi in mechanical pulping are the substantial energy reduction and the improved paper strength properties obtainable but this is achieved at the expense of a lower brightness due to the formation of quinones, a lower light scattering ability and a lower yield. The technical difficulties (long pre-treatment times, addition of nutrients, inhibition of undesirable microorganisms etc.) to implement this technology in existing operations are also a serious drawback.

The white-rot fungi produce specific enzymes (e.g., peroxidases, laccases, cellulases) and low-molecular weight organic and inorganic compounds (e.g., reactive oxygen species, oxalic acid, quinones, dihydroxybenzenes, veratryl alcohol) that have been proposed to be involved in the biodegradation mechanism (Hattori, Shimada 2001; Hammel et al. 2002; Li 2003). Enzymes are generally believed to be too large to be able to penetrate the unmodified wood cell wall (Kirk, Cullen 1998) and reactive oxygen species (e.g., hydroxyl radicals, $\mathrm{HO} \bullet$, peroxyl radicals, $\mathrm{ROO} \bullet$, hydroperoxyl radicals, HOO•) are therefore believed to initiate decay within the wood cell wall (Hammel et al. 2002; Henry 2003). Hydrogen peroxide, that can be produced by enzymes present in the white-rot fungi (e.g., aryl alcohol oxidase, glyoxal oxidase, pyranose 2-oxidase, cellobiose dehydrogenase), is believed to be the likely precursor for the hydroxyl radical (Li 2003). Ferrous iron $\left(\mathrm{Fe}^{2+}\right)$ reacts with the formed hydrogen peroxide and generates hydroxyl radicals in a process referred to as the Fenton reaction. White-rot fungi have developed different systems to reduce the formed ferric iron $\left(\mathrm{Fe}^{3+}\right)$ to $\mathrm{Fe}^{2+}$, e.g., via low molecular mass glycopeptides, dihydroxybenzenes or cellobiose dehydrogenase (Rodriguez et al. 2003). This means that the fungal degradation proceeds via redox cycles. The involvement of the Fenton reaction in the early phase of lignin biodegradation by white-rot fungi is, at present, debated and it has been reported that it is of no importance (Bohlin 2008).

The present investigation describes the potential of using Fenton-type chemistry for reducing the specific energy consumption during production of Black spruce (Picea mariana) TMP. Acid hydrogen peroxide was used as oxidant and ferrous sulphate as activator in the employed chemical system. The effect of using sodium oxalate/oxalic acid, ethylenediaminetetraacetic acid and 3,4-dimethoxybenzyl (veratryl) alcohol as enhancers are also discussed.

\section{Experimental}

\section{Materials}

Industrial wood chips of Black spruce (Picea mariana) obtained from Wisconsin, USA, were used in the present study. The chips had a dry content of $54 \%$ and a dry bulk density of $155 \mathrm{~kg} / \mathrm{m}^{3}$.

The hydrogen peroxide $\left(\mathrm{H}_{2} \mathrm{O}_{2}, 50 \%\right)$ was supplied by Arkema Chemicals, TN, USA, and the ferrous sulphate, 7-hydrate $\left(\mathrm{FeSO}_{4} \times 7 \mathrm{H}_{2} \mathrm{O},>99.5 \%\right)$ by Mallinckrodt Baker, NJ, USA. The 3,4-dimethoxybenzyl (veratryl) alcohol $\left[\left(\mathrm{CH}_{3} \mathrm{O}\right)_{2} \mathrm{C}_{6} \mathrm{H}_{3} \mathrm{CH}_{2} \mathrm{OH}, \mathrm{VA}, 97 \%\right]$ was obtained from Alfa Aesar, MA, USA, the oxalic acid, 2-hydrate $\left[(\mathrm{COOH})_{2} \times 2 \mathrm{H}_{2} \mathrm{O},>99.5 \%\right]$ from Reagents Inc., $\mathrm{NC}$, USA, the sodium oxalate $\left(\mathrm{Na}_{2} \mathrm{C}_{2} \mathrm{O}_{4},>99.95 \%\right)$ and the sodium salt of ethylenediaminetetraacetic acid, 2-hydrate $\left(\mathrm{Na}_{4}\right.$ EDTA $\times 2 \mathrm{H}_{2} \mathrm{O},>99 \%$ ) were both from Mallinckrodt Baker. The ratio between the enhancer and ferrous sulphate was about 1:1 (mole:mole). Sulphuric acid was used to lower the $\mathrm{pH}$ of the acid thermomechanical pulp reference (TMP Acid Ref, cf. Table 1 for explanation of abbreviations).

\section{Pilot plant trial}

Thermomechanical pulp (TMP) was produced at Andritz pilot plant facility in Springfield, $\mathrm{OH}$, USA. A three-stage refining setup was used and the energy input was varied in the last refining stage to obtain pulps with different freeness levels. The wood chips were pre-heated at 4.14 bar steaming pressure for 40 seconds prior to refining. A single disc 36" pressurized refiner (Andritz Sprout-Bauer 36-1 CP run at $1800 \mathrm{rpm}, 4.14$ bar) was used in the first refining stage and a double disc 36" atmospheric refiner (Andritz Sprout-Bauer 401, $1200 \mathrm{rpm}$ ) in the second and third refining stages. The energy input in the primary refining stage was about $500 \mathrm{kWh} / \mathrm{t}$, and in the second refining stage approximately $1000 \mathrm{kWh} / \mathrm{t}$. In most cases, three tertiary refining stages with a targeted energy input of 400,800 and $1200 \mathrm{kWh} / \mathrm{t}$ were performed. The energy consumption for producing the Black spruce reference TMP in the pilot plant was close to commercial operation (cf. Jackson, Wild 1999). The specific energy consumption is given as kWh per bone dry ton of pulp (bdt).

The chemicals used in the trial were added according to an inter-stage approach; the ferrous sulphate (and enhancer when used) was added to the refiner eye and 
hydrogen peroxide to the blow line of the pressurized first-stage refiner. The ferrous sulphate and the enhancer were thoroughly mixed before addition to the refiner eye. The pilot plant is a batch process, which inevitably leads to a retention time between the first and the second refining stage of at least 20 minutes, something that may have an impact on the chemical reactions prevailing. All trial series were run at constant conditions, meaning that the variation in specific energy consumption and resulting pulp and paper properties is a result of the chemicals added during the trial. The addition levels of chemicals are given as $100 \%$ calculated on bone dry wood.

\section{Analyses}

The physical and optical properties of the pulp and paper samples were tested on washed pulps (about 3\% pulp consistency at room temperature) in accordance with TAPPI standard procedures (T $205 \mathrm{sp}-06$, T $220 \mathrm{sp}-96, \mathrm{~T}$ 227 om-04, T 425 om-06, T 525 om-06) and the fibre length distribution was determined with a Kajaani FS100 fibre size analyzer. The metal ion content of the wood and pulps were determined after wet combustion with nitric acid using a microwave system with an ICP (inductively coupled plasma) instrument (Iris radiell, Thermo ICP s/n 10973). The report limits (mg/kg) were: $\mathrm{Ca}, 20 ; \mathrm{Cu}, 0.1 ; \mathrm{Fe}, 0.5 ; \mathrm{Mg}, 20$; and $\mathrm{Mn}, 0.1$. Residual hydrogen peroxide was determined by iodometric titration where the liberated iodine was titrated with $0.1 \mathrm{M}$ sodium thiosulphate.

The chemical oxygen demand (COD) was determined after a thorough water wash at $70^{\circ} \mathrm{C}$. The pulp $(15 \mathrm{~g}$ bone dry) was suspended in $900 \mathrm{ml}$ of deionised water for 30 seconds and then dewatered on a wire cloth Monodur PA 112 (from Derma). The filtrate was recirculated once to avoid loss of fibres and fines material. The procedure was repeated once and the two filtrates were combined and used for determining the COD value with a Dr. Lange XION 500 spectrophotometer and according to the method for Dr. Lange Classic COD Cuvette Test. The pulp yield ( $\%$, bone dry) was then determined from the COD value according to $E q$ [1], which is based on Bertolotti et al. (1982) and Åkerlund (1978).

$$
\text { Pulp yield }(\%)=\frac{1000}{C O D(\mathrm{~kg} / \mathrm{t}) \times 1.3+1000} \times 100
$$

\section{Result and Discussion}

\section{Acid hydrogen peroxide}

The acid hydrogen peroxide system described below has been used in this investigation to chemically modify high-freeness Black spruce (Picea mariana) thermomechanical pulp (TMP) with the aim of lowering the electrical energy consumption during subsequent refining. One hypothesis is that the radicals formed when hydrogen peroxide decomposes under acid conditions attack the outer fibre surfaces and weaken these cell wall layers and thereby facilitate the fibre development and lowering the energy needed to a certain degree of pulp refinement.

The combination of hydrogen peroxide $\left(\mathrm{H}_{2} \mathrm{O}_{2}\right)$ and a ferrous salt (i.e., Fenton's reagent) is known as an effective oxidant of a variety of organic compounds (Walling 1975; Sychev, Isak 1995). The Fenton reaction refers to the decomposition of hydrogen peroxide to highly reactive hydroxyl radicals ( $\mathrm{HO} \bullet$ ) via a reaction pathway involving soluble ferrous iron $\left(\mathrm{Fe}^{2+}\right)$ at an acidic $\mathrm{pH}$, see Reaction [1] in Fig 1. The formed ferric iron $\left(\mathrm{Fe}^{3+}\right)$ can slowly be transformed to $\mathrm{Fe}^{2+}$ by a Fenton-like reaction consuming $\mathrm{H}_{2} \mathrm{O}_{2}$ under the formation of hydroperoxyl radicals $(\mathrm{HOO} \cdot)$, [2]-[3], or by a reductant such as ascorbic acid, [4]. This means that the ferrous iron is recycled and can act as a catalyst in the oxidation system. The formed hydroxyl radical may also oxidize $\mathrm{Fe}^{2+}$ to $\mathrm{Fe}^{3+}$, [5], or decompose $\mathrm{H}_{2} \mathrm{O}_{2}$ to water and $\mathrm{HOO}$, Reaction [6]. The formed hydroperoxyl radicals can react with both the ferric, [7], and ferrous iron, [8], or decompose to a superoxide anion radical $\left(\mathrm{O}_{2} \bullet\right)$, Reaction [9]. Superoxide anion radicals are dominant at neutral $\mathrm{pHs}$ and may generate hydroxyl radicals by decomposition of hydrogen peroxide, Reaction [10] in Fig 1. The formed hydroxyl and hydroperoxyl radicals may also combine and generate hydrogen peroxide according to Reactions [11], [12] and [13]. Organic compounds (RH) such as lignocellulosic materials can be oxidized in radical chain reactions according to Reactions [14] and [15]. A combi-

$$
\begin{aligned}
& \mathrm{Fe}^{2+}+\mathrm{HOOH} \rightarrow \mathrm{Fe}^{3+}+\mathrm{HO} \cdot+\mathrm{OH}^{-} \\
& \mathrm{Fe}^{3+}+\mathrm{HOOH} \rightleftharpoons \mathrm{Fe}(\mathrm{HOO})^{2+}+\mathrm{H}^{+} \\
& \mathrm{Fe}(\mathrm{HOO})^{2+} \rightarrow \mathrm{Fe}^{2+}+\mathrm{HOO} \\
& \mathrm{Fe}^{3+}+\text { Reductant } \rightarrow \mathrm{Fe}^{2+}+\text { Reductant }{ }^{+} \\
& \mathrm{Fe}^{2+}+\mathrm{HO} \cdot \longrightarrow \mathrm{Fe}^{3+}+\mathrm{OH}^{-} \\
& \mathrm{HOOH}+\mathrm{HO} \cdot \rightarrow \mathrm{H}_{2} \mathrm{O}+\mathrm{HOO} \cdot \\
& \mathrm{Fe}^{3+}+\mathrm{HOO} \cdot \rightarrow \mathrm{Fe}^{2+}+\mathrm{O}_{2}+\mathrm{H}^{+} \\
& \mathrm{Fe}^{2+}+\mathrm{HOO} \rightarrow \mathrm{Fe}^{3+}+\mathrm{HOO}^{-} \\
& \mathrm{HOO} \cdot \rightarrow \mathrm{O}_{2}^{-} \cdot+\mathrm{H}^{+} \\
& \mathrm{O}_{2}^{-} \cdot+\mathrm{H}_{2} \mathrm{O}_{2} \rightarrow \mathrm{O}_{2}+\mathrm{OH}^{-}+\mathrm{HO} \cdot \\
& \mathrm{HO} \cdot+\mathrm{HO} \cdot \longrightarrow \mathrm{HOOH} \\
& 2 \mathrm{HO} \cdot+2 \mathrm{HOO} \cdot \longrightarrow 2 \mathrm{HOOH}+\mathrm{O}_{2} \\
& \mathrm{HOO} \cdot+\mathrm{HOO} \cdot \longrightarrow \mathrm{HOOH}+\mathrm{O}_{2} \\
& \mathrm{HO} \cdot+\mathrm{RH} \rightarrow \mathrm{H}_{2} \mathrm{O}+\mathrm{R} \cdot \\
& \mathrm{R} \cdot+\mathrm{HOOH} \rightarrow \mathrm{ROH}+\mathrm{HO} \cdot \\
& \mathrm{R} \cdot+\mathrm{R} \cdot \longrightarrow \mathrm{R}-\mathrm{R} \\
& \mathrm{R} \cdot+\mathrm{Fe}^{3+} \rightleftharpoons \mathrm{R}^{+}+\mathrm{Fe}^{2+} \\
& \mathrm{R} \cdot+\mathrm{Fe}^{2+} \rightleftharpoons \mathrm{R}^{-}+\mathrm{Fe}^{3+}
\end{aligned}
$$

Fig 1. Decomposition of hydrogen peroxide at an acidic $\mathrm{pH}(\mathrm{RH}=$ Organic compound). 
nation of the formed carbon centred radicals (dimerization), oxidation or reduction of the iron present is also possible, [16]-[18]. The catalysis of hydrogen peroxide decomposition by iron in dilute solutions is, however, not at present fully elucidated and the role of the hydroxyl radical is disputed. Besides the theory described above, which is based on the participation of free radicals, a conceptually different theory exists where the ferryl ion $\left(\mathrm{FeO}^{2+}\right)$ is regarded as the active intermediate and not the hydroxyl radical (cf. Sychev, Isak 1995).

The Fenton system is very complex and $\mathrm{pH}$, temperature and concentration dependent and is further complicated if organic substrates are present in the system. The reactions are influenced by the inorganic anions, the ligand attached to the metal ion and the nature of the organic compounds present. Different ferrous and ferric iron complexes and the numerous radical intermediates, generated oxidation products (e.g., alkyl and alkoxyl radicals, hydroxylated derivatives and carboxylic acids) and consecutive reactions make it even more complicated. It is also known that the Fenton system can be broadened to other lower valence transition metals which have one-electron redox couples [e.g., $\mathrm{Co}(\mathrm{I}) / \mathrm{Co}(\mathrm{II})$, $\mathrm{Cu}(\mathrm{I}) / \mathrm{Cu}(\mathrm{II}), \mathrm{Mn}(\mathrm{II}) / \mathrm{Mn}$ (III), Ti(III)/Ti(IV)] and organic hydroperoxides (e.g., alkyl hydroperoxides, ROOH) or hypohalous acids (e.g., $\mathrm{HOCl}$ ). More information about Fenton and Fenton-like systems can be found in Haber and Weiss (1934), Barb et al. (1951a,b), Walling (1975), Edwards and Curci (1992), Sychev and Isaak (1995), Goldstein and Meyerstein (1999) and De Laat (2004) and references cited therein.

The nature (e.g., metal chelating capability) and diversity (e.g., in chemical constituents) of the lignocellulosic material (i.e., wood) further adds complexity to the studied acid hydrogen peroxide system. The elucidation of the reactions of the lignocellulosic material occurring during the chosen experimental conditions is not the scope for this work but will be addressed in forthcoming studies.

Sodium oxalate/oxalic acid (abbreviated Ox in text, figures and tables) was chosen as an enhancer in the chemical system since it is known that oxalate is produced by wood degrading fungi (Goodell et al. 2002; Henry 2003) and several research groups have shown that sodium oxalate/oxalic acid has the potential to lower the specific energy consumption during refining (Swaney et al. 2003; Meyer et al. 2005). One prerequisite of using oxalic acid/sodium oxalate, however, is that the addition level is low so that possible problems with deposits are minimized. Ethylenediaminetetraacetic acid, sodium salt ( $\mathrm{Na}_{4}$ EDTA) was used as an enhancer to examine the possibility to reduce the well-known discoloration caused by iron (Janson, Forsskåhl 1989; Ni et al. 1997; Ni et al. 1998; Ni et al. 1999; Peart, Ni 2001). Furthermore, it is at present debated whether the hydroxyl radical formation in the Fenton reaction decreases or increases in the presence of chelating agents such as EDTA (Walker et al. 1999; Li et al. 2007). Veratryl alcohol (3,4-dimethoxybenzyl alcohol, VA) is one of the proposed ligands that participate in the complex reactions that prevail during biodegradation of wood (Hattori, Shimada 2001).
Veratryl alcohol is transformed into a veratryl alcohol cation radical $\left(\mathrm{VA}^{+} \bullet\right.$ ) which could degrade the wood constituents. Veratryl alcohol was tested as an enhancer since it may direct the oxidation towards the lignin constituent.

\section{Addition of chemicals during refining}

Chemicals used in order to lower the specific energy consumption (SEC) during refining can be added in various positions in a mechanical or chemimechanical pulping process. One alternative is to add chemicals before fibre separation (i.e., in a pre-treatment step) another is to add chemicals in-between or during refining (inter-stage treatment). The first approach could have the potential to influence the fibre separation mechanism and thereby the resulting pulp properties to a greater extent than the second approach, and has the drawback of being more capital intensive since some type of impregnation equipment normally is needed. The second approach, e.g., to use the primary refiner as mixing equipment, has the advantage of being cheaper and could directly be applicable in a thermomechanical pulping process consisting of two or more refiners in series. The potential of reducing energy could still be considerable for an interstage approach if the first refining stage is performed with a low energy input. This is supported by the fact that most of the energy used in a high-yield pulping process is consumed for fibre development (flexibilisation, fibrillation, generation of high-quality fine material, etc.) and not for fibre separation (Campbell 1934; Kano et al. 1983; Sundholm 1993). Furthermore, the addition of chemicals to the refiner is a well known technique and is used for bleaching purposes (Strunk, Meng 1989; Chute et al. 1995).

The acid hydrogen peroxide system used in this investigation was evaluated as an inter-stage treatment. The activator ferrous sulphate (and enhancer when used) was added to the refiner eye and hydrogen peroxide to the blow line of the pressurized first-stage refiner. A TMP produced at standard $\mathrm{pH}$-conditions $(\mathrm{pH} \mathrm{4.8,} \mathrm{denoted}$ TMP Ref) and a TMP produced under more acidic conditions ( $\mathrm{pH}$ 3.8, TMP Acid Ref) were used as references. The low-pH TMP reference was chosen since the acid hydrogen peroxide system lowers the $\mathrm{pH}$ of the resulting pulp (cf. Table 2), something that could influence (i.e., decrease) the specific energy consumption (Rachor et al. 1990; Forsskåhl et al. 1999).

Table 1 shows the amount of chemicals added during the pilot plant trial. Two hydrogen peroxide levels (about 1 and $2 \%$ ) and two ferrous sulphate levels (0.08 and $0.14-0.15 \%$ ) were tested. The charge of ferrous sulphate was rather high but was chosen to be sure that all of the added hydrogen peroxide was consumed during refining. When using this activator, sulphate ions are introduced and the risk of scaling, in the form of calcium sulphate, may increase. However, other types of ferrous iron containing activators not containing sulphate ions can be used. Three of the trial series also included an enhancer (oxalic acid/sodium-oxalate, $\mathrm{Na}^{4}$ EDTA or veratryl alcohol). The ratio between the enhancer and ferrous sulphate was about 1:1 (mole:mole) and the enhancer and 
ferrous sulphate were thoroughly mixed before addition to the inlet of the refiner.

Table 2 shows the amount of residual hydrogen peroxide and the $\mathrm{pH}$ value for the different trial series at different positions in the TMP line. Most of the added hydrogen peroxide is still left after the primary refining stage (i.e., shortly after addition) and in most cases there is still peroxide present after the secondary refining stage. Especially addition of $\mathrm{Na}_{4}$ EDTA slows down the consumption of hydrogen peroxide. It is also clear that all, or nearly all, of the added hydrogen peroxide was consumed during fibre processing. The $\mathrm{pH}$ value of the acid hydrogen peroxide-treated thermomechanical pulps was in the range of 3.2-3.7. The lower $\mathrm{pH}$ is a consequence of the addition of hydrogen peroxide, ferrous sulphate and probably also to the formation of low-molecularweight organic acids during the course of the reaction (cf. Manini et al. 2006).

The metal ion content of the wood chips and thermomechanical pulps with a freeness value of approximately $100 \mathrm{ml} \mathrm{CSF}$ can be found in Table 3. The iron content increased from $13 \mathrm{mg} / \mathrm{kg}$ for the wood chips to 25 and 64 $\mathrm{mg} / \mathrm{kg}$ for the TMP Ref and TMP Acid Ref, respectively. This is an effect of the iron content in process waters and the release of iron from process equipment. The trial series, with a low addition charge of ferrous sulphate (HP A and HP C series), had an iron content between 160 and $180 \mathrm{mg} / \mathrm{kg}$ and the trial series with a high addition charge of ferrous sulphate (HP B and HP D series) had an iron content between 290 and $320 \mathrm{mg} / \mathrm{kg}$. These iron levels correlate well with the amount of iron that was introduced via the ferrous sulphate addition. Theoretically, the low and high addition levels of ferrous sulphate should increase the iron content with approximately 160 and 280 $\mathrm{mg} / \mathrm{kg}$, respectively. Furthermore, there is enrichment in the calcium and magnesium content during refining whereas the manganese content decreased with $15-35 \%$ (cf. Table 3).

\section{Specific energy consumption (SEC)}

The acid hydrogen peroxide system was evaluated for its possibility to lower the specific energy consumption during production of Black spruce TMP. One way of doing the assessment is to compare the specific energy consumption to a certain degree of pulp refinement, and Fig $2 a$ shows the freeness as a function of SEC. It is evident that a substantial energy reduction is obtained with the chemical system and that the extent of electrical energy saved primarily is a function of the applied amount of hydrogen peroxide. There was no significant difference between the two TMP references (TMP Ref and TMP Acid Ref) when it comes to energy consumption, i.e., the lower $\mathrm{pH}$ of the acid hydrogen peroxide system can not explain the reduction in SEC. At a freeness level of $100 \mathrm{ml} \mathrm{CSF}$ (newsprint grade pulp), about 20\% lower SEC was obtained with a hydrogen peroxide addition of $1 \%$ (trial series HP A and HP B) and about 35\% with a hydrogen peroxide addition of $2 \%$ (series HP C and HP D). No clear effect of increasing the amount of ferrous sulphate could be seen, something that indicates
Table 1. The chemicals used for each trial series.

\begin{tabular}{|c|c|c|c|}
\hline \multirow[t]{2}{*}{ Trial series } & \multicolumn{3}{|c|}{ Added chemicals [\% of bone dry wood] } \\
\hline & $\mathrm{H}_{2} \mathrm{O}_{2}$ & $\mathrm{FeSO}_{4} \times 7 \mathrm{H}_{2} \mathrm{O}$ & Enhancer \\
\hline TMP Ref & n.a. ${ }^{1}$ & n.a. ${ }^{1}$ & n.a. ${ }^{1}$ \\
\hline TMP Acid Ref ${ }^{2}$ & n.a. ${ }^{1}$ & n.a. ${ }^{1}$ & n.a. ${ }^{1}$ \\
\hline $\mathrm{HPA}$ & 1.0 & 0.08 & n.a. ${ }^{1}$ \\
\hline $\mathrm{HPB}$ & 1.1 & 0.15 & n.a. ${ }^{1}$ \\
\hline $\mathrm{HPC}$ & 2.2 & 0.08 & n.a. ${ }^{1}$ \\
\hline HP D & 2.1 & 0.14 & n.a. ${ }^{1}$ \\
\hline HP A Ox & 1.0 & 0.08 & $\begin{array}{c}0.04 \text { Oxalic acid } \\
0.04 \text { Sodium oxalate }\end{array}$ \\
\hline HP A EDTA & 1.1 & 0.08 & $0.12 \mathrm{Na}_{4}$ EDTA \\
\hline HP DVA & 2.0 & 0.14 & 0.09 Veratryl alcohol \\
\hline
\end{tabular}

'n.a. = no addition

${ }^{2}$ The $\mathrm{pH}$ was adjusted by adding $0.19 \%$ (of bone dry wood) $\mathrm{H}_{2} \mathrm{SO}_{4}$ to the refiner eye

Table 2. The residual hydrogen peroxide content and $\mathrm{pH}$ value at various positions in the TMP line.

\begin{tabular}{lcccccc}
\hline Trial series & \multicolumn{2}{c}{$\begin{array}{c}\text { After 1st } \\
\text { ref. stage }\end{array}$} & \multicolumn{2}{c}{$\begin{array}{c}\text { After 2nd } \\
\text { ref. stage }\end{array}$} & \multicolumn{2}{c}{ Final pulp } \\
& $\mathbf{H}_{2} \mathbf{O}_{2}(\%)$ & pH & $\mathbf{H}_{2} \mathbf{O}_{2}(\%)$ & pH & $\mathbf{H}_{2} \mathbf{O}_{2}(\%)$ & pH \\
\hline TMP Ref & n.a. ${ }^{1}$ & 4.8 & n.a. ${ }^{1}$ & n.d. $^{2}$ & n.a. ${ }^{1}$ & 4.9 \\
TMP Acid Ref & n.a. ${ }^{1}$ & 3.8 & n.a. ${ }^{1}$ & n.d. ${ }^{2}$ & n.a. ${ }^{1}$ & 3.8 \\
HP A & 0.78 & 5.1 & 0.31 & 3.9 & 0.07 & 3.6 \\
HP B & 0.78 & 3.9 & 0 & 3.5 & 0 & 3.4 \\
HP C & 1.97 & 4.3 & 0.34 & 3.3 & 0.04 & 3.3 \\
HP D & 1.89 & 4.0 & 0.38 & 3.3 & 0 & 3.2 \\
HP A Ox & 0.88 & 4.2 & 0 & 3.5 & 0 & 3.3 \\
HP A EDTA & 0.92 & 4.8 & 0.94 & 4.2 & 0 & 3.7 \\
HP D VA & 1.99 & 4.1 & 0.40 & 3.2 & 0.03 & 3.2 \\
\hline
\end{tabular}

${ }^{1}$ n.a. $=$ no addition

${ }^{2}$ n.d. $=$ not determined

Table 3. The freeness value and metal ion content of wood chips and selected pulps.

\begin{tabular}{lcccccc}
\hline Trial series & $\begin{array}{c}\text { Freeness } \\
\text { [ml CSF }\end{array}$ & \multicolumn{5}{c}{ Metal ion content $[\mathrm{mg} / \mathrm{kg}]$} \\
& & $\mathrm{Ca}$ & $\mathrm{Cu}$ & $\mathrm{Fe}$ & $\mathbf{M g}$ & $\mathrm{Mn}$ \\
\hline Wood chips & n.a. ${ }^{1}$ & 910 & 0.1 & 13 & 110 & 95 \\
TMP Ref & 119 & 1100 & 0.2 & 25 & 250 & 82 \\
TMP Acid Ref & 91 & 1100 & 0.5 & 64 & 250 & 76 \\
HP A & 109 & 1100 & $<0.1$ & 170 & 250 & 75 \\
HP B & 75 & 1000 & 0.2 & 320 & 220 & 66 \\
HP C & 116 & 1000 & 0.2 & 160 & 200 & 71 \\
HP D & 109 & 960 & $<0.1$ & 310 & 200 & 62 \\
HP A Ox & 98 & 1100 & 0.4 & 180 & 250 & 69 \\
HP A EDTA & 118 & 1100 & $<0.1$ & 160 & 250 & 71 \\
HP D VA & 108 & 1100 & 0.6 & 290 & 220 & 74 \\
\hline
\end{tabular}

${ }^{1}$ n.a. $=$ not applicable

that even the low addition level of ferrous sulphate was too high for the hydrogen peroxide charge used. None of the tested enhancers (oxalic acid/sodium oxalate, $\mathrm{Na}_{4}$ EDTA or veratryl alcohol) influenced the specific energy consumption to any significant extent. The difference in saved amount of energy between the two hydrogen peroxide addition levels was less pronounced for magazine paper grade pulps (<50 ml CSF, Fig $2 a)$.

It is important that the refining conditions are constant to be able to conclude that the effects seen are a consequence of the added chemicals and not a consequence of varying refining conditions. The energy input in the primary refiner was similar for all trial series (cf. 


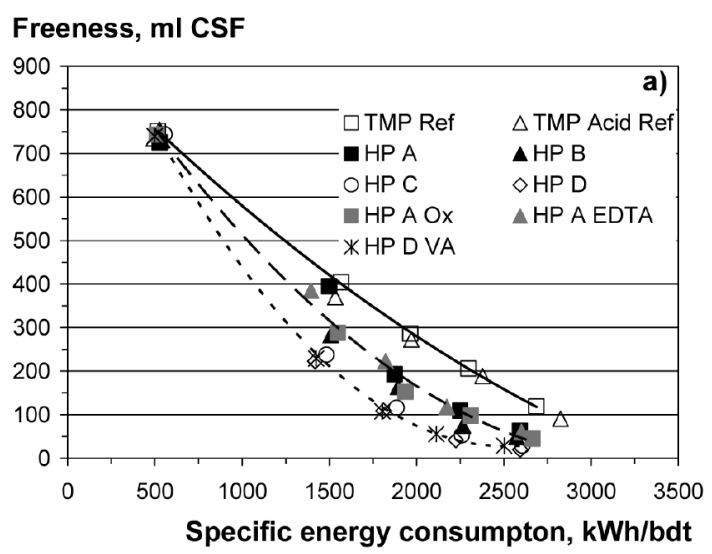

Tensile index, $\mathrm{Nm} / \mathrm{g}$

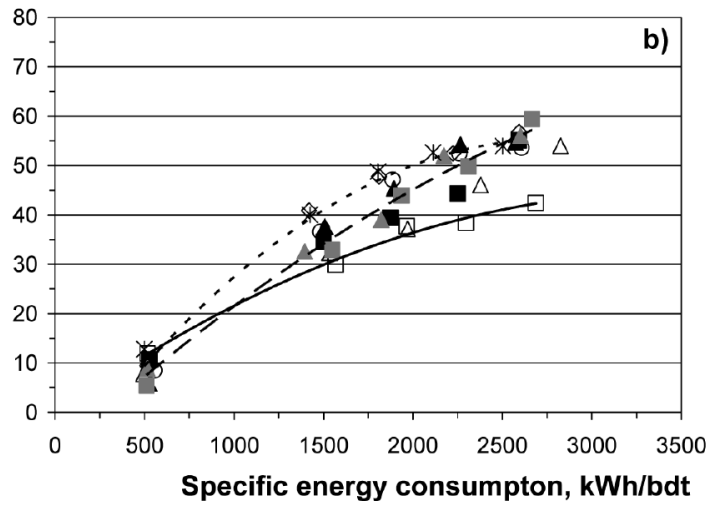

Figs 2a-b. Freeness (a) and tensile index (b) as a function of the specific energy consumption for TMP references and acid hydrogen peroxide-treated pulps. The amount of chemicals used in each trial series can be found in Table 1. Trend lines are drawn for the TMP reference and the acid hydrogen peroxide-treated pulps ( $1 \%$ and $2 \% \mathrm{H}_{2} \mathrm{O}_{2}$ ), respectively. The legends are given in Fig $2 \mathrm{a}$.

Figs 2a-b) and the refining conditions employed were as constant as possible, which indicates that the obtained energy reduction is in fact a consequence of the employed acid hydrogen peroxide system.

The freeness value gives an indication of the drainability of the pulp and it is influenced by, e.g., the specific surface and volume of fibres and fine materials, the fibre length distribution and the fibre stiffness. Two pulps with the same freeness value could differ greatly from each other when it comes to pulp properties such as paper strength. It is therefore essential not only to compare the electrical energy consumption at a constant freeness level, but also at a constant strength property or other pulp and paper property that is essential for the intended end-product. For example, if a reduction in SEC is accompanied by a loss of pulp quality (e.g., strength), the cost to maintain end-product quality will increase (e.g., cost for reinforcement pulp and/or strength additives). The cost reduction obtained by decreasing the electrical energy consumption must then be corrected and compared with the cost of a reference pulp of equal quality.

If a comparison is made between the TMP reference (TMP Ref) and the acid hydrogen peroxide-treated pulps (HP series) at a constant tensile index of $45 \mathrm{Nm} / \mathrm{g}$ instead of a constant freeness value of $100 \mathrm{ml} \mathrm{CSF}$, the same general conclusions can be made, i.e., the low peroxide addition level (trial series HP A and HP B) saves about $25 \%$ and the
Fibre length (Iw), mm

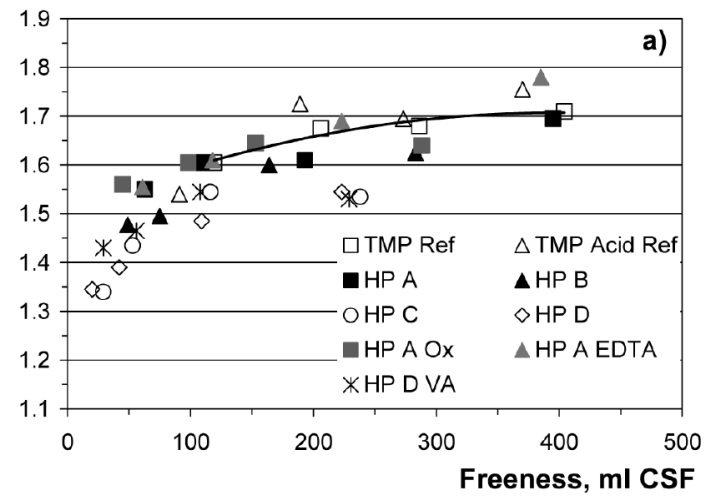

Fibre length (Iw), mm

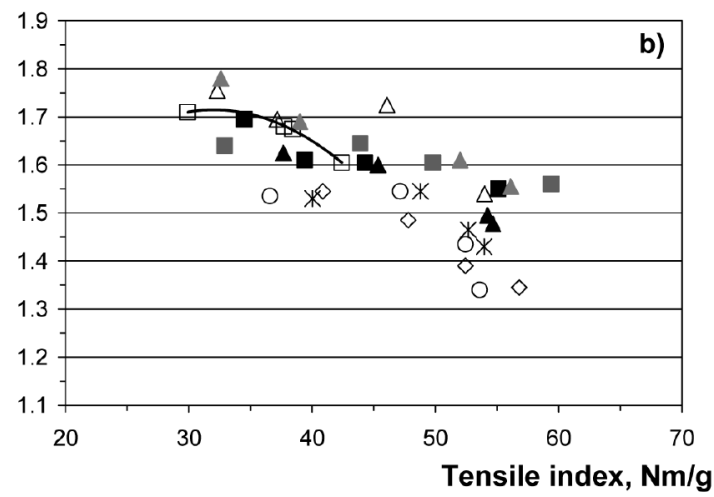

Figs 3a-b. The average fibre length (length weighted) as a function of freeness (a) and tensile index (b) for TMP references and acid hydrogen peroxide-treated pulps. The amount of chemicals used in each trial series can be found in Table 1. A trend line is drawn for the TMP reference. The legends are given in Fig $3 a$.

high addition level (HP C and HP D) about 35\% of the electrical energy used for refining (cf. Fig 2b).

One obvious way of reducing the energy consumption to a fixed freeness value during production of TMP is to cut the fibres (cf. Johansson, Dahlqvist 2001), something that is undesirable since a pulp with long, flexible and well fibrillated fibres normally has a good potential to produce strong paper. Furthermore, strong high-yield pulps need no or little of the expensive reinforcement (chemical) pulp in the paper furnish. Among other things, this will improve the cost and printing performance of the end-product. Fig $3 a$ shows the average fibre length (length weighted) as a function of the degree of refinement (freeness). At a freeness level of $100 \mathrm{ml} \mathrm{CSF}$, no change in average fibre length was detectable when $1 \%$ hydrogen peroxide and $0.08 \%$ iron sulphate were added (HP A trial series, cf. Table 1) whereas an addition of $2 \%$ hydrogen peroxide (HP C and HP D series) entailed a minor reduction with about 5\%. At lower freeness levels (less than $50 \mathrm{ml} \mathrm{CSF}$ ), a larger reduction in fibre length was obtained for some of the trial series. It is also evident from Fig $3 b$ that, at a constant tensile index, the average fibre length is shorter for the trial series with a hydrogen peroxide charge of $2 \%$.

The fractional composition, divided into long, middle and fines fractions, was determined in the Bauer McNett classifier and since the average fibre length was rather 
Tensile index, $\mathrm{Nm} / \mathrm{g}$

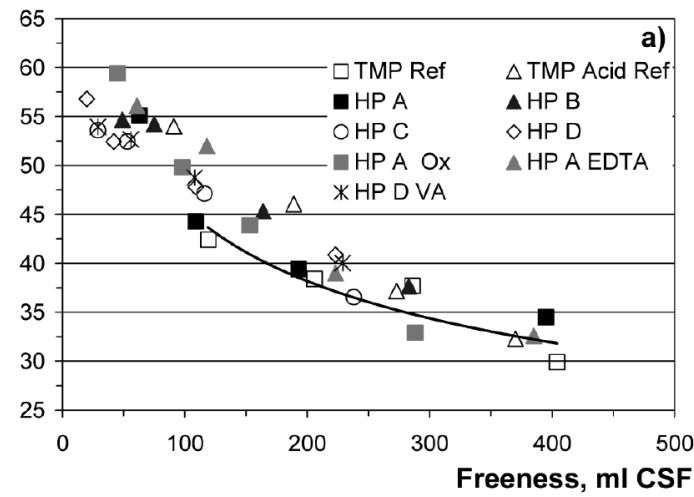

Tensile index, $\mathrm{Nm} / \mathrm{g}$

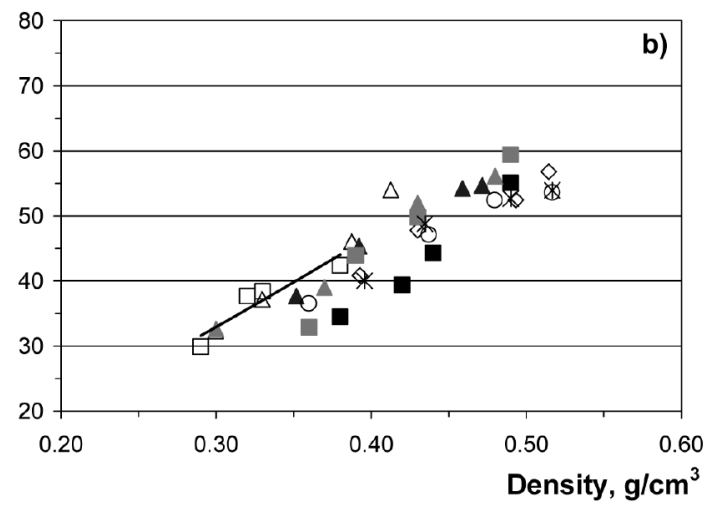

Figs 4a-b. The tensile index as a function of freeness (a) and density (b) for TMP references and acid hydrogen peroxide-treated pulps. The amount of chemicals used in each trial series can be found in Table 1. A trend line is drawn for the TMP reference. The legends are given in Fig $4 a$

similar, no significant difference between the fractional compositions was expected. A high hydrogen peroxide charge generated somewhat more middle fraction (28$200)$ and slightly less long fibre fraction (+28), something that is consistent with the results from the fibre length measurements. Also the fines fraction (-200) is somewhat lower after chemical treatment. The coarsest fibres (Bauer McNett fraction +14) are the fibres that are considered to be the most detrimental and that may cause unevenness in the paper surface; something that may result in inferior printing performance. The amount of these fibres was very similar for all of the pulps suitable for printing paper applications. The shive content (Pulmac $0.10 \mathrm{~mm}$ ) of the reference and acid hydrogen peroxide TMPs was also very similar at freeness levels below $400 \mathrm{ml} \mathrm{CSF}$.

\section{Strength properties}

The strength properties of mechanical or chemimechanical pulps are of the utmost importance and influence the cost of the resulting wood-containing paper, runability on the paper machine and printing press and the end-performance of the produced paper and paperboard product (e.g., dimensional stability, printability, dusting and linting tendencies). A method that reduces the electrical energy consumption during production of high-yield pulps is therefore of limited interest for the pulp and
Tear index, $\mathrm{mNm}^{2} / \mathrm{g}$

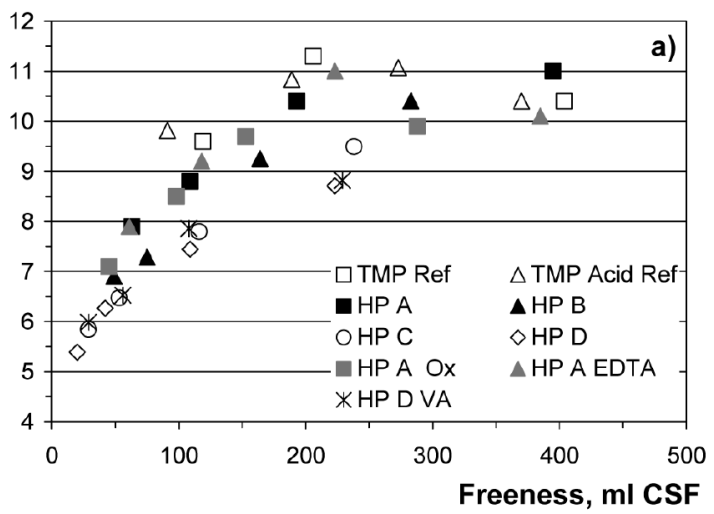

Tear index, $\mathrm{mNm}^{2} / \mathrm{g}$

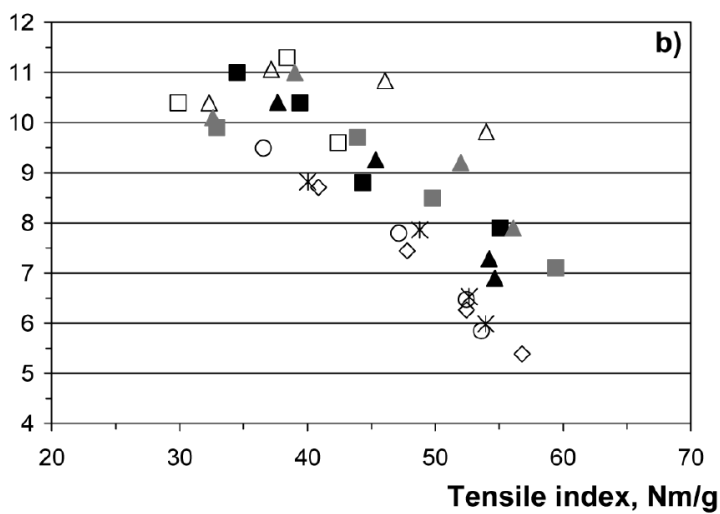

Tear index, $\mathrm{mNm}^{2} / \mathrm{g}$

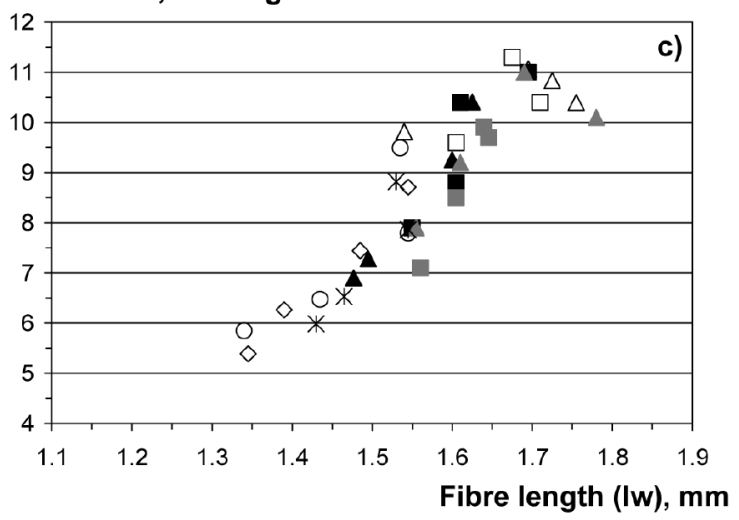

Figs 5a-c. The tear index as a function of freeness (a), tensile index (b) and fibre length (c) for TMP references and acid hydrogen peroxide-treated pulps. The amount of chemicals used in each trial series can be found in Table 1. The legends are given in Fig $5 a$.

paper industry if it simultaneously leads to a substantial reduction in the physical properties of the pulp/paper.

Fig $4 a$ shows the tensile index as a function of freeness. At a freeness value of $100 \mathrm{ml} \mathrm{CSF}$, the tensile index for the chemically treated pulps is the same or higher than the tensile index for the TMP Ref. A slight reduction in tensile index may be seen for a hydrogen peroxide addition level of 2\% (series HP C and HP D) at lower freeness values when compared to the TMP Acid Ref.

The tensile index is normally a function of the density of the paper sheet. When looking at Fig $4 b$, it is evident that the tensile-density relationship is somewhat different 
for the acid hydrogen peroxide-treated pulps (HP series) compared to the reference pulps (TMP Ref and TMP Acid Ref). The chemically treated pulps have a higher density (lower bulk) at a fixed tensile strength compared to the references. This may be a result of more flexible fibres with a high contact (bonding) area. The oxidative treatment could also lead to an increased fibre charge and thereby improved fibre bonding potential. The somewhat higher density could be negative for products where a high bulk (stiffness) is desirable (e.g., paper board applications).

The tear strength is influenced by the fibre length, the strength of the individual fibres and by the bonding ability of the fibre material. The chemical inter-stage treatment lowers the tear index by $5-10 \%$ and about $20 \%$ for the low (1\%) and high (2\%) addition level of hydrogen peroxide, respectively, when the comparison is made at a freeness value of $100 \mathrm{ml} \mathrm{CSF} \mathrm{(Fig} \mathrm{5a).} \mathrm{When} \mathrm{com-}$ paring with the TMP Acid Ref at a tensile index of 50 $\mathrm{Nm} / \mathrm{g}$, the reduction in tear index is between 15 and $30 \%$ depending on the amount of hydrogen peroxide added (Fig $5 b$ ). The lower tear strength could be explained by a reduction in fibre length (Fig 5c), and possibly also to some reduction of the internal fibre strength. This is not unlikely, since radicals are generated during the hydrogen peroxide decomposition (cf. Fig 1). In summary, the acid hydrogen peroxide system evaluated makes it possible to produce a newsprint quality thermomechanical pulp from Black spruce with improved tensile strength and somewhat lower tear strength using 20\% less electrical energy compared to a reference TMP.

\section{Optical properties}

The optical properties of high-yield pulps are becoming more and more important since the brightness (whiteness) requirements for improved newsprint and many uncoated and coated magazine paper grades (e.g., SC, LWC, MWC) have been raised during recent years. Hence, the brightness (and brightness stability) of a pulp are important quality parameters and should not be altered in a detrimental way if possible.

Fig 6 shows the brightness and Figs 7-8 the light scattering and light absorption coefficients as a function of the degree of pulp refinement for the different trial series. The brightness increases slightly when the freeness value decreases, something that is a consequence of an increased light scattering ability of the pulps (cf. Fig 7). With the amount of chemicals applied in this trial, the acid hydrogen peroxide system lowers the brightness considerably. At a freeness level of $100 \mathrm{ml} \mathrm{CSF}$, the HP A EDTA and HP A series lose 6 and 7 ISO brightness units compared to the references (TMP Ref, TMP Acid Ref) whereas the brightness decrease is more than 9 brightness units for the rest of the trial series. The decrease in brightness is to some extent a consequence of the addition of ferrous sulphate, which increases the light absorption coefficient (Fig 8). The slightly lower light scattering ability for most of the acid hydrogen peroxidetreated pulps also contributes to the brightness decrease. The variation in light scattering coefficient is, however, large
Brightness, \%

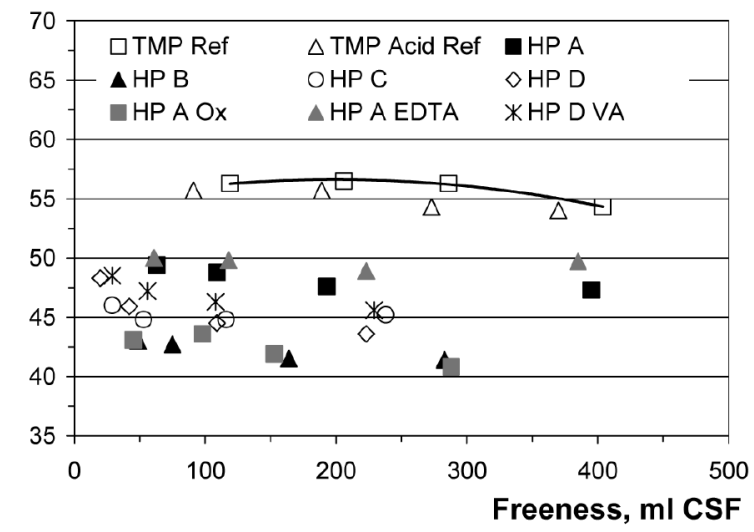

Fig 6. The brightness as a function of freeness for TMP references and acid hydrogen peroxide-treated pulps. The amount of chemicals used in each trial series can be found in Table 1. A trend line is drawn for the TMP reference.

\section{Light scattering coefficient, $\mathrm{m}^{2} / \mathbf{k g}$}

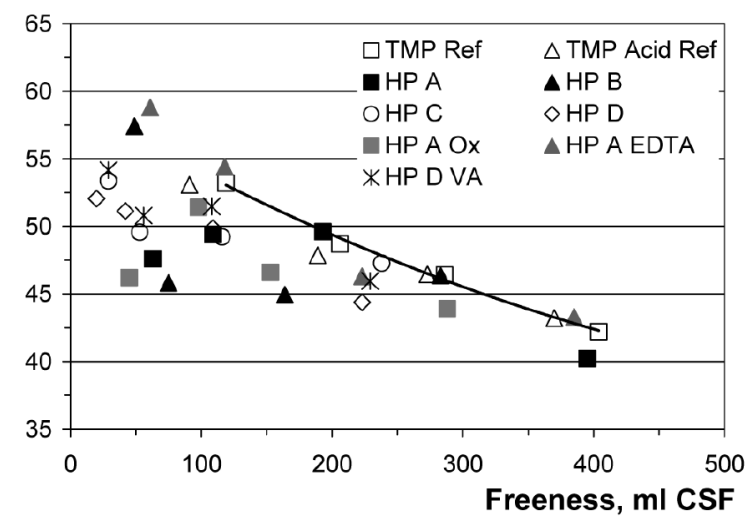

Fig 7. The light scattering coefficient (at $557 \mathrm{~nm}$ ) as a function of freeness for TMP references and acid hydrogen peroxide-treated pulps. The amount of chemicals used in each trial series can be found in Table 1. A trend line is drawn for the TMP reference.

\section{Light absorption coefficient, $\mathrm{m}^{2} / \mathrm{kg}$}

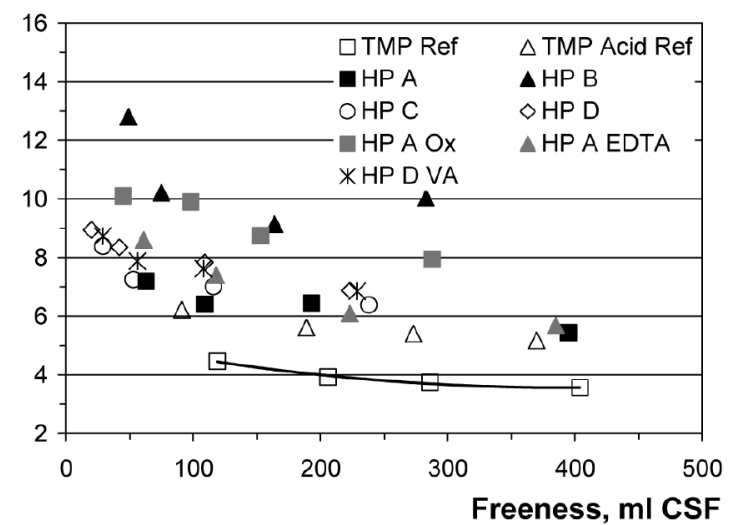

Fig 8. The light absorption coefficient (at $557 \mathrm{~nm}$ ) as a function of freeness for TMP references and acid hydrogen peroxide-treated pulps. The amount of chemicals used in each trial series can be found in Table 1. A trend line is drawn for the TMP reference.

for the chemically treated pulps especially at low freeness values. The effect of using enhancers is small; $\mathrm{Na}_{4}$ EDTA and veratryl alcohol increased the brightness somewhat whereas oxalic acid/sodium oxalate generated a darker pulp. There could be several explanations for the discoloration 
that occurs. One obvious reason is the precipitation of iron salts when the $\mathrm{pH}$ is raised and another the generation of ferric iron during the course of the reaction. The formation of coloured ferric complexes with wood constituents is another plausible explanation and it is well-known that many lignin-metal and extractive-metal complexes are highly coloured (Janson, Forsskåhl 1989; $\mathrm{Ni}$ et al. 1997; Ni et al. 1998; Ni et al. 1999; Peart, Ni 2001). The formed radicals (cf. Fig 1) may also generate new lignocellulosic structures that directly or indirectly (together with metal ions) contribute to the observed discoloration. It is clear that the amount of ferrous sulphate added in the system affects the discoloration, and since the addition level of ferrous sulphate most likely was too high (cf. discussion above), the possibility to diminish the discoloration should be considerable. The potentially lower brightness stability due to the high iron content in the acid hydrogen peroxide-treated pulps (cf. Table 3) should not be overlooked and future studies of the chemical system should consider this. The removal (washing, chelating) of iron from the chemically treated pulps, thereby regaining some of the brightness that was lost as well as the bleachability under oxidative and reductive conditions of the same pulps, has been presented elsewhere (Walter et al. 2009).

\section{Released organic substances}

There is no simple and straightforward way to determine the pulp yield in a mechanical or chemimechanical pulping process. The measured pulp yield is dependent on many factors such as wood raw material, processing conditions, pulping principle and the extent of washing. Most of the wood constituents that are dissolved during processing can be found in process waters and effluents as dissolved substances or as colloidal particles. In addition, volatile organic compounds (e.g., terpenes, lowmolecular weight alcohols, organic acids) are released during processing. Normally, the unbleached pulp yield for softwood thermomechanical pulps are about 96-97\% (Holmbom et al. 2005).

In the present investigation, the pulp yield of the

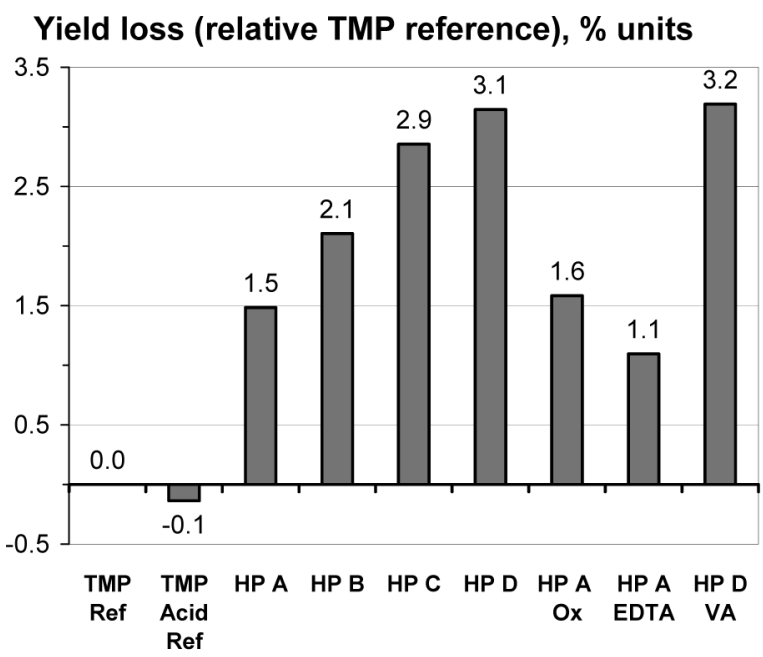

Fig 9. The pulp yield loss (=yield TMP Rei $_{1} \%$ - yield Trial series, $_{\text {, }} \%$ for acid TMP reference and acid hydrogen peroxide-treated pulps with a freeness value of approximately $100 \mathrm{ml} \mathrm{CSF}$ (cf. Table 3). The amount of chemicals added in the different trial series can be found in Table 1. chemically treated pulps was determined as the yield loss relative the yield of the TMP Ref. The yield was calculated from the COD (chemical oxygen demand) value obtained after a thorough and standardized washing procedure as described in the Experimental section. Fig 9 shows the yield loss for pulps with freeness values of approximately $100 \mathrm{ml} \mathrm{CSF}$. The acid hydrogen peroxide system generated a yield loss of approximately 1-3\% units depending on the amount of chemicals added. The enhancer $\mathrm{Na}_{4}$ EDTA seems to have a slightly positive effect in preserving the pulp yield.

In summary, the chemical system evaluated in this paper demonstrates that it is possible to significantly reduce the electrical energy consumption during the refining of softwood TMP and that this can be done without any extensive change in the tensile strength of the resulting pulp. The main drawback is the lower brightness and pulp yield. The discoloration can, however, to a large extent be removed by hydrogen peroxide bleaching as described elsewhere (Walter et al. 2009). The acid hydrogen peroxide system employed is complex and more work is needed to fully utilize the potential of the treatment. A thorough chemical and morphological characterization of the acid hydrogen peroxide-treated Black spruce (Picea mariana) thermomechanical pulps will therefore be presented in a forthcoming paper in order to better explain the prevailing effects shown in this work.

\section{Conclusions}

Acid hydrogen peroxide (i.e., $\mathrm{H}_{2} \mathrm{O}_{2}$ and $\mathrm{FeSO}_{4}$ ) used as an inter-stage treatment in the thermomechanical pulping process has proven to be effective in reducing the specific energy consumption for Black spruce (Picea mariana) wood. A reduction of approximately $20-35 \%$ to a freeness value of $100 \mathrm{ml} \mathrm{CSF}$ seems possible to reach using $1-2 \% \quad \mathrm{H}_{2} \mathrm{O}_{2}$ with only marginally changed fibre length, fractional composition of the pulp or tensile strength of the paper. The brightness of the treated pulps was, however, reduced. The amount of ferrous sulphate added in the system affects the pulp brightness and, since the addition level of ferrous sulphate most likely was too high during the trial, the possibility of lowering the discoloration should be considerable when the chemical system is optimized.

\section{Acknowledgements}

Financial support from the Knowledge Foundation is gratefully acknowledged. The authors thank Professor Per Engstrand, Mid Sweden University, Sundsvall, Sweden for valuable discussions.

\section{References}

Agarwal, U.P. and Akhtar, M. (2000): Understanding fungus-induced brightness loss of biomechanical pulps, Pulping/Process and Product Quality Conf., Boston, MA, USA, November 5-8, TAPPI, Atlanta, GA, USA, 12pp.

Akamatsu, I., Yoshihara, K., Kamishima, H. and Fujii, T. (1984): Influence of white-rot fungi on poplar chips and thermo-mechanical pulping of fungi-treated chips (in Japanese), Mokuzai Gakkaishi, 30(8), 697-702. 
Akhtar, M., Attridge, M.C., Myers, G.C. and Blanchette, R. A. (1993): Biomechanical pulping of loblolly pine chips with selected white-rot fungi, Holzforschung. 47(1), 36-40.

Akhtar, M., Blanchette, R.A., Myers, G. and Kirk, T.K. (1998): An overview of biomechanical pulping research, In: Young, R. A. and Akhtar, M. (eds.), Environmentally Friendly Technologies for the Pulp and Paper Industry, John Wiley and Sons, Inc., New York, NY, USA, pp. 309-340.

Ali (Viforr), S. and Salmén, L. (2005): From wood shavings to mechanical pulp - A new raw material?, Nord. Pulp Paper Res. J. 20(4), 418-422.

Ander, P. and Eriksson, K.-E. (1975): Mechanical pulp from pre-rotten chips: An introductory study (in Swedish), Svensk Papperstidning, 78(18), 641-642.

Axelson, P. and Simonson, R. (1983): Thermomechanical pulping with low addition of sulfite. Part 4. A mill scale trial, Svensk Papperstidning, 86(15), R149R151.

Barb, W.G., Baxendale, J.H., George, P. and Hargrave, K.R. (1951a): Reactions of ferrous and ferric ions with hydrogen peroxide. Part I-The ferrous ion reaction, Trans. Faraday Soc. 47, 462-500.

Barb, W.G., Baxendale, J.H., George, P. and Hargrave, K.R. (1951b): Reactions of ferrous and ferric ions with hydrogen peroxide. Part II-The ferric ion reaction, Trans. Faraday Soc. 47, 591-616.

Bar-Lev, S.S., Kirk, T.K. and Chang, H.-M. (1982): Fungal treatment can reduce energy requirements for secondary refining of TMP, Tappi J. 65(10), 111-113.

Bertolotti, H., Lüttgen, W. and Göttsching, L. (1982): Definition and determination of the loss of yield in mechanical pulping (in German), Papier, 36(3), 105-111.

Bohlin, C. (2008): In Vitro and in Vivo Oxidation of Diastereomers of Lignin Models of Arylglycerol b-Aryl Ether Type and Heterologous Expression of Laccase. Ph.D. thesis 2008:9, Karlstad University, Karlstad, Sweden.

Campbell, W.B. (1934): Groundwood studies; Theoretical efficiency, Pulp Paper Can. 35(4), 218-219.

Cannell, E. (1999): Mechanical pulping technologies. Focus on reducing refining energy, Pulp and Paper, 73(5) 63-66, 69-70.

Chute, W.E., MacConnachie, P.T.F. and Barna, J. (1995): Reductive refiner bleaching at Slave Lake Pulp, 28th Annual Pulp Pap. Meeting, Sao Paulo, Brazil, November 6-10, Associacao Brasileira Tecnica de Cellulose e Papel, Sao Paulo, Brazil, pp. 135-145.

De Laat, J., Le, G.T. and Legube, B. (2004): A comparative study of the effects of chloride, sulfate and nitrate ions on the rates of decomposition of $\mathrm{H}_{2} \mathrm{O}_{2}$ and organic compounds by $\mathrm{Fe}(\mathrm{II}) / \mathrm{H}_{2} \mathrm{O}_{2}$ and $\mathrm{Fe}\left(\mathrm{III} / \mathrm{H}_{2} \mathrm{O}_{2}\right.$, Chemosphere, 55(5), 715-723.

Edwards, J.O. and Curci, R. (1992): Fenton type activation and chemistry of hydroxyl radical, In: Strukul, G. (ed.), Catalytic Oxidations with Hydrogen Peroxide as Oxidant, Kluwer Academic Publishers, Dordrecht, Netherlands, pp. 97-151.

Forsskåhl, I., Nurminen, I., and Korhonen, T. (1999): Effects of chemicals added during refining on thermomechanical pulp bleachability and brightness stability (in Finnish), PSC Communications 127, KCL Paper Science Centre, Espoo, Finland.

Francis, B., Towers, M. and Browne, T. (2006): Benchmarking energy use in pulp and paper operations, PAPTAC 92nd Annual Meeting, Montreal, Quebec, Canada, February 7-9, the Pulp and Paper Technical Association of Canada, Montreal, Quebec, Canada, Book A, pp. A55-A61.

Frazier, W.C. and Williams, G.J. (1982): Reduction of specific energy in mechanical pulping by axial precompression of wood, Pulp Paper Can. 83(6), T162T167.

Goldstein, S. and Meyerstein, D. (1999): Comments on the mechanism of the "Fenton-like" reaction, Acc. Chem. Res. 32(7), 547-550.

Goodell, B., Qian, Y., Jellison, J., Richard, M. and Qi, W. (2002): Lignocellulose oxidation by low molecular weight metal-binding compounds isolated from wood degrading fungi: A comparison of brown rot and white rot systems and the potential application of chelator-mediated Fenton reactions, In: Viikari, L. and Lanttoo, R. (eds.), Progress in Biotechnology, Vol. 21, Biotechnology in the Pulp and Paper Industry, Elsevier Press, Amsterdam, Netherlands, pp. 37-47.

Haber, F. and Weiss, J. (1934): The catalytic decomposition of hydrogen peroxide by iron salts, Proc. R. Soc. London, Ser. A 147(861), 332-351.

Hammel, K.E., Kapich, A.N., Jensen Jr., K.A. and Ryan, Z.C. (2002): Reactive oxygen species as agents of wood decay by fungi, Enzyme Microb. Technol. 30(4), 445-453.

Harrison, R., Parrish, T., Gibson, A., Knapp, C., Wajer, M. and Johnson, D.
(2008): Refiner bleaching with magnesium hydroxide $\left(\mathrm{Mg}(\mathrm{OH})_{2}\right)$ and hydrogen peroxide, Tappi J. 7(9), 16-20.

Hartler, N. (1980): How energy can be reduced in refiner mechanical pulping, Pulp Paper Can. 81(6), T119-T123.

Hattori, T. and Shimada, M. (2001): Microbial, enzymatic, and biomimetic degradation of lignin in relation to bioremediation, In: Hon, N.-S. and Shiraishi, N. (eds.), Wood and Cellulosic Chemistry, Marcel Dekker, Inc., New York, NY, USA, pp. 547-571.

Henry, W.P. (2003): Non-enzymatic iron, manganese, and copper chemistry of potential importance in wood decay, In: Goodell, B., Nicholas, D D. and Schultz, T. B. (eds.), Wood Deterioration and Preservation: Advances in our Changing World, ACS Symposium Series 845, American Chemical Society, Washington, DC, USA, pp. 175-195.

Höglund, H., Bäck, R., Falk, B. and Jackson, M. (1997): Thermopulp - A new energy-efficient mechanical pulping process, Pulp Paper Can. 98(6), T215-T222. Holmbom, B., Konn, J. and Pranovich, A. (2005): What is the true yield of TMP and CTMP? What is lost in bleaching?, 24th Int. Mech. Pulp. Conf., Oslo, Norway, June 7-9, PTF, Oslo, Norway, pp. 98-101.

Jackson, M. and Wild, N. W. (1999): Mechanical pulp mills, In: Williamson, P. N. (ed.), Energy Cost Reduction in the Pulp and Paper Industry, the Pulp and Paper Technical Association of Canada, Montreal, Quebec, Canada, pp. 97-118.

Janson, J. and Mannström, B. (1981): Principles of chemical pretreatment in the manufacture of CMP and CTMP from hardwood. Two stage chemical pretreatment is a necessity for birchwood, Pulp Paper Can. 82(4), T111-T116.

Janson, J. and Forsskåhl, I. (1989): Color changes in lignin-rich pulps on irradiation by light, Nord. Pulp Paper Res. J. 4(3), 197-205.

Johansson, L. and Dahlqvist, G. (2001): Energy reduction in different refining concepts, 22th Int. Mech. Pulp. Conf., Helsinki, Finland, June 4-8, KCL, Helsinki, Finland, pp. 557-564.

Kano, T., Iwamida, T. and Sumi, Y. (1983): Energy savings in mechanical pulping, Int. Symp. Wood Pulp. Chem., Tsukuba Science City, Japan, May 23-27, JTAPPI, Tokyo, Japan, Vol. 2, pp. 5-10.

Kirk, T.K. and Cullen, D. (1998): Enzymology and molecular genetics of wood degradation by white-rot fungi, In: Young, R. A. and Akhtar, M. (eds.), Environmentally Friendly Technologies for the Pulp and Paper Industry, John Wiley and Sons, Inc., New York, NY, USA, pp. 273-307.

Kure, K.-A., Dahlqvist, G., Sabourin, M.J. and Helle, T. (1999): Development of spruce fibre properties by a combination of a pressurized compressive pretreatment and high intensity refining, 21th Int. Mech. Pulp. Conf., Houston, TX, USA, May 24-26, TAPPI, Atlanta, GA, USA, pp. 427-433.

Leatham, G.F., Myers, G.C. and Wegner, T.H. (1990): Biomechanical pulping of aspen chips: Energy savings resulting from different fungal treatments, Tappi J. 73(5), 197-200.

Li, K. (2003): The role of enzymes and mediators in white-rot fungal degradation of lignocellulose, In: Goodell, B., Nicholas, D. D. and Schultz, T. B. (eds.), Wood Deterioration and Preservation: Advances in our Changing World, ACS Symposium Series 845, American Chemical Society, Washington, DC, USA, pp. 196-209.

Li, L., Yoshihiro, A., Kiyotada, K., Tomoko, S., Tadahiko, M., Masataka, M., Miho, T. and Naoki, M. (2007): Iron-chelating agents never suppress Fenton reaction but participate in quenching spin-trapped radicals, Anal. Chim. Acta, 599(2), 315-319.

Manini, P., La Pietra, P., Panzella, L., Napolitano, A. and d'Ischia, M. (2006): Glyoxal formation by Fenton-induced degradation of carbohydrates and related compounds, Carbohydr. Res. 341(11), 1828-1833.

Mansfield, S.D. (2002): Laccase impregnation during mechanical pulp processing - Improved refining efficiency and sheet strength, Appita J. 55(1), 49-53.

Meyer, V., Ruel, K., Kurek, B. and Petit-Conil, M. (2005): Oxalate: A microbial metabolite of interest for the pulping industry, Rev. ATIP 59(4), 6-8, 10-12.

Münster, H. and Dahlqvist, G. (1995): Operational experience with the first commercial high speed refiner at Perlen Papier AG, Switzerland, 19th Int. Mech. Pulp. Conf., Ottawa, Ontario, Canada, June 12-15, CPPA, Montreal, Quebec, Canada, pp. 197-202.

Münster, H., Ferritsius, 0., Lecourt, M. and Petit-Conil, M. (2005): Energy savings in TMP by high temperature LC/MC refining, 24th Int. Mech. Pulp. Conf., Oslo, Norway, June 7-9, PTF, Oslo, Norway, pp. 219-223.

Musselman, R., Letarte, D., Simard, R. and Lachance, C. (1996): Third stage low 
consistency refining of TMP for newsprint/directory grades, 50th APPITA Annual General Conf., Auckland, New Zealand, May 6-10, Technical Association of the Australia and New Zealand Paper Industry, Carlton, Australia, Vol. 1, pp. 363-368.

Ni, Y., Li, Z. and van Heiningen, A.RP. (1997): Minimization of the brightness loss due to metal ions in process water for bleached mechanical pulps, 83rd Annual Meeting, Technical Section CPPA, Montreal, Quebec, Canada, January 3031, CPPA, Montreal, Quebec, Canada, Vol. B, pp. B43-B49.

$\mathrm{Ni}$ Y., Ghosh, A., Li, C., Heitner, C. and McGarry, P. (1998): Photostabilization of bleached mechanical pulps with DTPA treatment, J. Pulp Paper Sci. 24(8), 259-263.

$\mathrm{Ni}, \mathrm{Y} ., \mathrm{Ng}, \mathrm{A}$. and Mosher, M. (1999): A Model compound study: The formation of colored metallic extractive complexes and their effect on brightness of TMP pulp, J. Wood Chem. Technol. 19(3), 213-223.

Peart, C. and Ni, Y. (2001): UV-Vis spectra of lignin model compounds in the presence of metal ions and chelants, J. Wood Chem. Technol. 21(2), 113-125.

Peng, F., Ferritsius, R. and Ängsås, U. (2003): Mechanical pulping with pectinase pretreatment of wood chips, 23th Int. Mech. Pulp. Conf., Quebec, Quebec, Canada, June 2-5, Pulp and Paper Technical Association of Canada, Montreal, Quebec, Canada, pp. 335-340.

Pere, J., Siika-Aho, M. and Viikari, L. (2000): Biomechanical pulping with enzymes: Response of coarse mechanical pulp to enzymatic modification and secondary refining, Tappi J. 83(5), 8pp.

Petit-Conil, M. and de Choudens, C. (1998): Ozone in the production of softwood and hardwood high-yield pulps to save energy and improve quality, Nord. Pulp Paper Res. J. 13(1), 16-22.

Rachor, G., Patt, R. and Horand, D. (1990): Untersuchungen zur Energieeinsparung bei der Herstellung von CTMP, Papier, 44(10A), V1-V10.

Rodden, G. (2003): Energy efficiency is still the focus, Pulp Paper Int. 45(5), 13-17. Rodriguez, J., Ferraz, A. and de Mello, M. P. (2003): Role of metals in wood biodegradation, In: Goodell, B., Nicholas, D. D. and Schultz, T. B. (eds.), Wood Deterioration and Preservation: Advances in our Changing World, ACS Symposium Series 845, American Chemical Society, Washington, DC, USA, pp. 154-174.

Sabourin, M.J. (1998): Evaluation of a compressive pre-treatment process on TMP properties and energy requirements, 84th Annual Meeting, Technical Section CPPA, Montreal, Quebec, Canada, January 27-30, CPPA, Montreal, Quebec, Canada, Vol. B, pp. B41-B50.

Sabourin, M. (2007): Minimizing TMP energy consumption using a combination of chip pre-treatment, RTS and multiple stage low consistency refining, 25th Int. Mech. Pulp. Conf., Minneapolis, MN, USA, May 6-9, TAPPI, Atlanta, GA, USA, 8 pp. Sabourin, M., Cort, J.B., Musselman, R. and Ryan, K. (1996): Effect of residence time, temperature and speed on TMP properties produced from radiata pine and black spruce/balsam fir wood furnishes, 50th APPITA Annual General Conf., Auckland, New Zealand, May 6-10, Technical Association of the Australian and New Zealand Paper Industry, Carlton, Australia, Vol. 2, pp. 567-577.

Setliff, E.C., Marton, R., Granzow, S.G. and Eriksson, K.L. (1990): Biomechanical pulping with white-rot fungi. Tappi J. 73(8), 141-147.

Strunk, W.G. and Meng, P. (1989): Status report: Pulp bleaching with hydrogen peroxide during refining, In: Patrick, K.L. (ed.), Modern Mechanical Pulping in the Pulp and Paper Industry, Miller Freeman Publications, San Fransisco, CA, USA, pp. 169-173.

Sundholm, J. (1993): Can we reduce energy consumption in mechanical pulping?, 18th Int. Mech. Pulp. Conf., Oslo, Norway, June 15-17, PTF, Oslo, Norway, pp. 133-142.

Swaney, R., Akhtar, M., Horn, E., Lentz, M. and Sabourin, M. (2003): Oxalic acid pretreatment for mechanical pulping greatly improves paper strength while maintaining scattering power and reducing shives and triglycerides, TAPPI Fall Technical Conf., Chicago, IL, USA, October 26-30, TAPPI, Atlanta, GA, USA, 5pp.

Sychev, A. Ya. and Isak, V. G. (1995): Iron compounds and the mechanisms of the homogenous catalysis of the activation of $\mathrm{O}_{2}$ and $\mathrm{H}_{2} \mathrm{O}_{2}$ and of the oxidation of organic substrates, Russian Chem. Rev. 64(12), 1105-1129.

Vesterlind, E.-L. and Höglund, H. (2006): Chemithermomechanical pulp made from birch at high temperature, Nord. Pulp Paper Res. J. 21(2), 216-221.

Viljakainen, E. (2006): High-quality mechanical pulps in paper and board manufacture, Int. Papwirtsch. (9), 47-51.

Walker, C.C., Dinus, R.J., McDonough, T.J. and Eriksson, K.-E.L. (1999): Use of an improved chemiluminescence assay for non-intrusive measurement of hydroxyl radicals in a biomimetic pulp bleaching system, Holzforschung, 53(2), 181-187.

Walling, C. (1975): Fenton's reagent revisited, Acc. Chem. Res. 8(4), 125-131.

Walter, K., Paulsson, M. and Wackerberg, E. (2009): Energy efficient refining of Black spruce TMP by using acid hydrogen peroxide: Part 2. Washing, chelating and bleaching studies, Nord. Pulp Paper Res. J. 24(3), 266-272.

Åkerlund, G. (1978): Pulp-yield measurement simplified with new technique, Defibrator News 78(2).

Åkerlund, G., Danielsson, 0., Falk, B. and Ryrberg, G. (1979): Defibrator bleaching - A new concept in TMP, 11th Int. Mech. Pulp. Conf., Toronto, Canada, June 11-14, CPPA, Montreal, Quebec, Canada, pp. 237-243.

Manuscript received February 13, 2009 Accepted March 25, 2009 